\title{
Effects of Verapamil and Ibutilide on Atrial Fibrillation and Postfibrillation Atrial Refractoriness
}

\author{
CHRISTIAN STICHERLING, M.D., WILlIAM HSU, Ph.D., * HIROSHI TADA, M.D.,* \\ ANTON C. BARES, B.S., * HAKAN ORAL, M.D.,* FRANK PELOSI, M.D.,* \\ BRADLEY P. KNIGHT, M.D.,* S. ADAM STRICKBERGER, M.D.,* \\ and FRED MORADY, M.D.*
}

From the Department of Internal Medicine II, Division of Cardiology, Free University of Berlin, Berlin, Germany; and the *Division of Cardiology, Department of Internal Medicine, University of Michigan Medical Center, Ann Arbor, Michigan

\begin{abstract}
Verapamil and Ibutilide. Introduction: Early recurrence of atrial fibrillation (AF) after cardioversion may be related to shortening of the atrial effective refractory period (ERP). This study compared the effects of verapamil and ibutilide on AF cycle length (AFCL), atrial ERP, and susceptibility to recurrent AF.

Methods and Results: In 33 adults, the atrial ERP was measured at basic drive CLs of 350 and 500 msec before and after a brief episode of pacing-induced AF. During AF, verapamil, ibutilide, or saline was infused in 11 patients each. Shortening of the post-AF atrial ERP was attenuated by verapamil and prevented by ibutilide. AFCL shortened by $32 \pm 21 \mathrm{msec}$ in the verapamil group $(P<0.01)$, prolonged by $44 \pm 14 \mathrm{msec}$ in the ibutilide group $(P<0.001)$, and did not change in the control group. AF converted to sinus rhythm within 10 minutes less often after verapamil $(0 \%)$ than after ibutilide $(82 \%)$ or than in the control group (73\%). Post-AF, AF lasting $>10$ minutes was induced more often in the verapamil group than in the ibutilide group $(26 \%$ vs $0 \% ; P=0.01)$. Another 10 patients received verapamil or ibutilide in the absence of AF. Atrial ERP was unchanged after verapamil and prolonged after ibutilide.

Conclusion: Verapamil shortens AFCL and impedes the conversion of induced AF, whereas ibutilide prolongs AFCL and does not impede the early conversion of induced AF. Ibutilide is more effective than verapamil in preventing post-AF shortening of the atrial ERP and reducing the susceptibility toward reinduction of AF. (J Cardiovasc Electrophysiol, Vol. 13, pp. 151-157, February 2002)
\end{abstract}

verapamil, ibutilide, atrial fibrillation, atrial refractoriness

\section{Introduction}

Atrial fibrillation (AF) shortens the atrial effective refractory period (ERP) and increases the susceptibility to further episodes of AF. ${ }^{1-3}$ Previous clinical and experimental studies demonstrated that verapamil attenuates these effects of AF. $2,4,5$ In accordance with these findings, verapamil has been shown to diminish the likelihood of immediate or early recurrence of AF. ${ }^{6-8}$ However, in another study, verapamil did not block the effects of AF on atrial electrophysiologic properties. ${ }^{9}$ Furthermore, verapamil may make AF more sustained. ${ }^{10}$

Ibutilide is useful for cardioversion of AF and facilitation of transthoracic cardioversion of AF.11-13 However, its effects on atrial electrophysiologic properties in patients with paroxysmal AF have not been defined. The purpose of the present study was to compare the effects of verapamil and ibutilide on AF, on AF-induced changes in atrial ERP, and on the susceptibility to reinduction of AF.

Supported in part by the Don Nouse Arrhythmia Research Fund. Dr. Sticherling was supported by the German Research Foundation.

Address for correspondence: Fred Morady, M.D., Division of Cardiology, Department of Internal Medicine, University of Michigan Medical Center, 1500 E. Medical Center Drive, B1F245, Ann Arbor, MI 48109-0022. Fax: 734-936-7026; E-mail: fmorady@ umich.edu

Manuscript received 30 November 2001; Accepted for publication 7 January 2002 .
Methods

\section{Characteristics of the Study Population}

The subjects of this study were 43 patients ( 7 men and 36 women; mean age $43 \pm 17$ years; $\pm 1 \mathrm{SD}$ ) referred to the University of Michigan Medical Center for radiofrequency catheter ablation of paroxysmal supraventricular tachycardia $(n=42)$ or idiopathic ventricular tachycardia $(n=1)$. All patients were in sinus rhythm, and none had a history of AF. Exclusion criteria consisted of a corrected QT interval $>440 \mathrm{msec}$, presence of structural heart disease, or recent treatment with amiodarone. Mean left ventricular ejection fraction was $0.6 \pm 0.02$.

\section{Study Protocol}

Treatment with antiarrhythmic drugs, including digoxin, beta-blockers, and calcium channel blockers, was discontinued at least five half-lives before the electrophysiologic procedure. The study protocol was approved by the Human Research Committee and performed with the patient's consent upon completion of the radiofrequency catheter ablation procedure.

A quadripolar electrode catheter was positioned in the right atrial appendage, where the mean pacing threshold was $0.8 \pm 0.1 \mathrm{~mA}$. Pacing was performed at three times threshold. Atrial ERP was measured at basic drive cycle lengths (CLs) of 350 and $500 \mathrm{msec}$ using drive trains of eight beats and a 1-second pause between pacing trains. The initial $S_{1} S_{2}$ interval was shorter than the ERP, and the $\mathrm{S}_{1} \mathrm{~S}_{2}$ interval was 
increased in steps of $5 \mathrm{msec}$ until there was atrial capture. ERP was defined as the longest $S_{1} S_{2}$ interval that failed to result in atrial capture. ERP measurements were repeated at each basic drive CL until three values were within $5 \mathrm{msec}$ of each other and then averaged.

Eleven patients were randomized to receive verapamil $0.1 \mathrm{mg} / \mathrm{kg}$ intravenously over 3 minutes, followed by an infusion of $0.005 \mathrm{mg} / \mathrm{kg} / \mathrm{min}$ over 7 minutes. ${ }^{14}$ A second group of 11 patients received ibutilide $0.02 \mathrm{mg} / \mathrm{kg}$ intravenously over a period of 10 minutes. This dosage was used because it provides a balance between optimal efficacy and safety, in a weight-adjusted fashion. ${ }^{15}$ The third group of 11 patients served as a control group and received normal saline $0.3 \mathrm{~mL} / \mathrm{kg}$ over 10 minutes.

At the onset of drug administration, AF was induced by rapid atrial pacing at $\mathrm{CL}=190 \mathrm{msec}$. Upon conversion to sinus rhythm, rapid pacing was immediately repeated to reinduce $A F$. After $\geq 5$ minutes of $A F$, the $A F$ was allowed to terminate spontaneously. Electrical cardioversion under deep sedation with midazolam and fentanyl was performed if the AF persisted for $>10$ minutes, which was the case in 16 patients. Drug infusion was stopped after 10 minutes or upon spontaneous cardioversion to sinus rhythm after $\geq 5$ minutes of AF. Total doses administered were verapamil $10.1 \pm 1.7 \mathrm{mg}$ and ibutilide $1.63 \pm 0.97 \mathrm{mg}$. Upon resumption of sinus rhythm, atrial ERP was repeatedly measured at alternating basic drive CLs of 350 and $500 \mathrm{msec}$. Elapsed time between resumption of sinus rhythm and each determination of atrial ERP was measured to the nearest second. ERP was measured ten times at each drive CL, for a total of 20 measurements.

To determine the effects of ibutilide and verapamil in the absence of AF, ibutilide $0.02 \mathrm{mg} / \mathrm{kg}$ (mean dose $1.7 \pm 0.2$ $\mathrm{mg}$ ) was infused over 10 minutes in five patients, and verapamil $0.1 \mathrm{mg} / \mathrm{kg}$ was infused over 3 minutes followed by an infusion of $0.005 \mathrm{mg} / \mathrm{kg} / \mathrm{min}$ over 7 minutes (mean dose $7.8 \pm 2.1 \mathrm{mg}$ ) in another five patients, during sinus rhythm. Upon completion of the infusion, atrial ERPs were measured in the same manner as in the patients in whom AF had been induced.

A secondary episode of AF was defined as an episode of AF that was unintentionally induced during measurement of ERP. Whenever a secondary episode of AF was induced, the elapsed time after resumption of sinus rhythm was noted and the duration of the episode was measured. In six patients, a secondary episode of AF persisted for $>10$ minutes, and electrical cardioversion was performed. In these patients, only the data collected before onset of the secondary episode of AF were used for analysis.

Blood pressure was measured with a brachial cuff before and after AF was induced and did not change significantly or differ between the groups.

\section{Analysis of AFCL}

AFCL was measured from two 30-second samples of the right atrial electrogram obtained immediately after induction of the primary episode of AF and 30 seconds before electrical or spontaneous cardioversion of this episode. A custom-written program in Matlab (MathWorks, Natick, MA, USA) was used to compute CL. Detection criteria for electrograms consisted of an amplitude threshold of $10 \%$ of the largest electrogram and an interval $>50 \mathrm{msec}$ from the previous electrogram. The longest and shortest $10 \%$ of CLs were discarded to remove outliers.

\section{Statistical Analysis}

Continuous variables are expressed as mean $\pm 1 \mathrm{SD}$. Groups were compared by analysis of variance with repeated measures. Bonferroni test was used for post hoc analysis. A paired $t$-test was used to compare the baseline and first post-AF ERPs. Categorical variables were compared by Chi-square analysis. $\mathrm{P}<0.05$ was considered statistically significant.

\section{Results}

\section{Baseline Atrial ERP}

There were no significant differences in baseline atrial ERPs between the verapamil, ibutilide, and control groups, either at a basic drive CL of $350 \mathrm{msec}(\mathrm{P}=0.3$; Table 1$)$, or $500 \mathrm{msec}(\mathrm{P}=0.1$; Table 2$)$.

\section{Duration of Induced $A F$}

Mean duration of the primary episode of induced AF was significantly longer in the verapamil group $(13.8 \pm 4.8 \mathrm{~min})$ than in the ibutilide group $(9.0 \pm 4.3 \mathrm{~min})$ or in the control group $(7.5 \pm 3.2 \mathrm{~min} ; \mathrm{P}<0.001)$. The primary episode of AF converted spontaneously within 10 minutes in none of the 11 patients in the verapamil group, which was significantly less often than in the ibutilide group $(9 / 11$ patients [82\%]; $\mathrm{P}<0.001)$, or in the control group (8/11 [73\%]; $\mathrm{P}<$ $0.001)$

\section{Mean AFCL}

Mean AFCL could be analyzed in 9 patients in the verapamil group, 8 patients in the ibutilide group, and 8 patients in the control group. During the first 30 seconds of induced AF, mean AFCL was significantly shorter in the verapamil group (155 $\pm 24 \mathrm{msec})$ than in the ibutilide $(202 \pm 23 \mathrm{msec})$ and control $(198 \pm 39 \mathrm{msec} ; \mathrm{P}<0.01)$ groups. During the last 30 seconds of induced AF, CL had shortened significantly in the verapamil group $(122 \pm 13$ msec; $\mathrm{P}=0.003)$, lengthened significantly in the ibutilide group $(241 \pm 21 \mathrm{msec} ; \mathrm{P}<0.01)$, and was unchanged in the control group $(207 \pm 32 \mathrm{msec} ; \mathrm{P}=0.4)$. The $\Delta$ AFCL was $33 \pm 21 \mathrm{msec}$ in the verapamil group, $-39 \pm 25 \mathrm{msec}$ in the ibutilide group, and $-9 \pm 25$ in the control group $(\mathrm{P}<0.001$; Figs. 1 and 2$)$.

\section{Change in ERP After AF}

Compared with baseline ERP, the first post-AF ERP in the verapamil group was significantly shorter at a drive CL of $350 \mathrm{msec}$, with rapid subsequent recovery (Table 1 and Fig. 3). At a drive CL of $500 \mathrm{msec}$, there was no post-AF shortening of atrial ERP (Table 2 and Fig. 4). In the ibutilide group, there was no shortening of atrial ERP at a drive CL of 350 msec (Table 1 and Fig. 3) or $500 \mathrm{msec}$ (Table 2 and Fig. 4).

Atrial ERPs in the ibutilide group lengthened and remained longer throughout the post-AF atrial ERP measurement period.

Atrial ERPs in the control group shortened significantly and recovered to a value not significantly different from the baseline measurement $4.2 \pm 1.1$ minutes after conversion to 

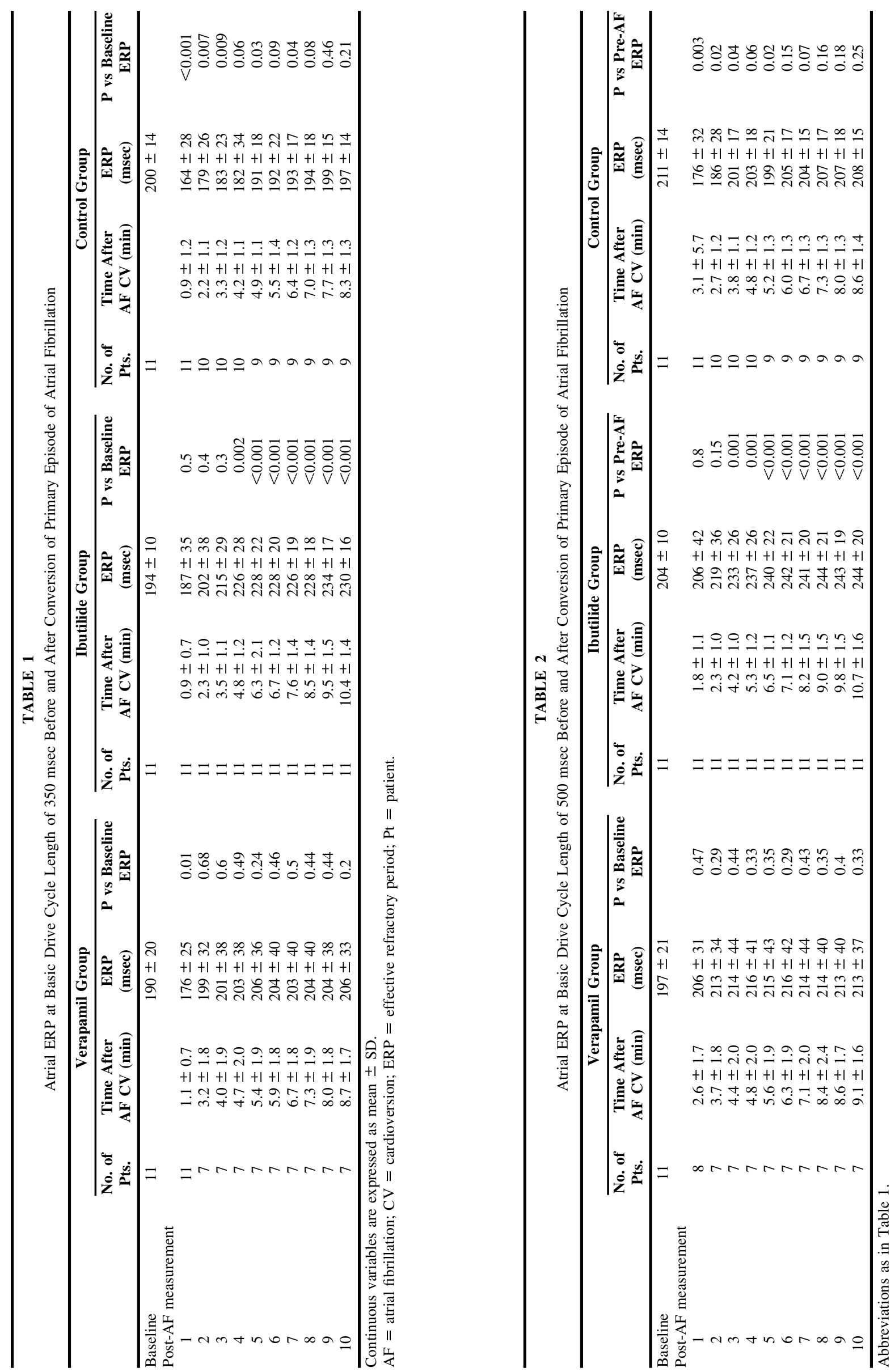
Verapamil

Ibutilide

Control

First 30 seconds
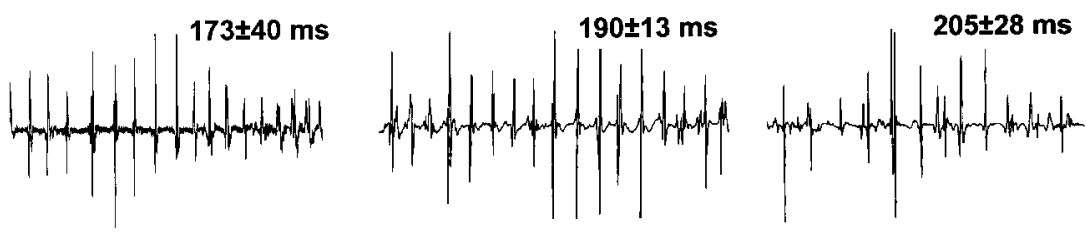

\section{Last 30 seconds}

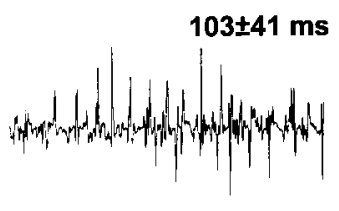

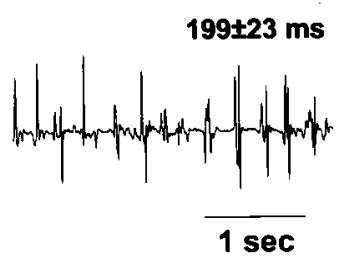

Figure 1. Examples of right atrial electrograms sampled during the first and last 30 seconds of induced atrial fibrillation after infusion of verapamil, ibutilide, and saline. Mean atrial fibrillation cycle lengths $( \pm 1$ $S D)$ are shown. sinus rhythm at a drive CL of $350 \mathrm{msec}$ (Table 1 and Fig. 3) and $4.8 \pm 1.6$ minutes after conversion to sinus rhythm at a drive CL of 500 msec (Table 2 and Fig. 4).

\section{Induction of Secondary Episodes of AF After Cardioversion}

A secondary episode of AF was induced during 7 (5\%) of 149 measurements of atrial ERP in the verapamil group, 4 (2\%) of 220 measurements in the ibutilide group $(\mathrm{P}=0.1$ vs verapamil), and $32(16 \%)$ of 202 measurements in the control group $(\mathrm{P}<0.001$ vs verapamil and ibutilide). Mean duration of secondary episodes of AF was significantly longer in the verapamil group $(6.6 \pm 6.1 \mathrm{~min})$ than in the ibutilide $(0.3 \pm 0.2 \mathrm{~min})$ and control $(0.9 \pm 2.5 \mathrm{~min})$ groups $(\mathrm{P}=0.04)$.

All post-AF episodes of secondary AF lasting $>10$ minutes were induced during the first post-AF measurement of atrial ERP. This occurred more often in the verapamil group $(26 \%)$ than in the ibutilide group $(0 \% ; \mathrm{P}<0.05)$, but not more often than in the control group $(5 \% ; \mathrm{P}=0.9)$.

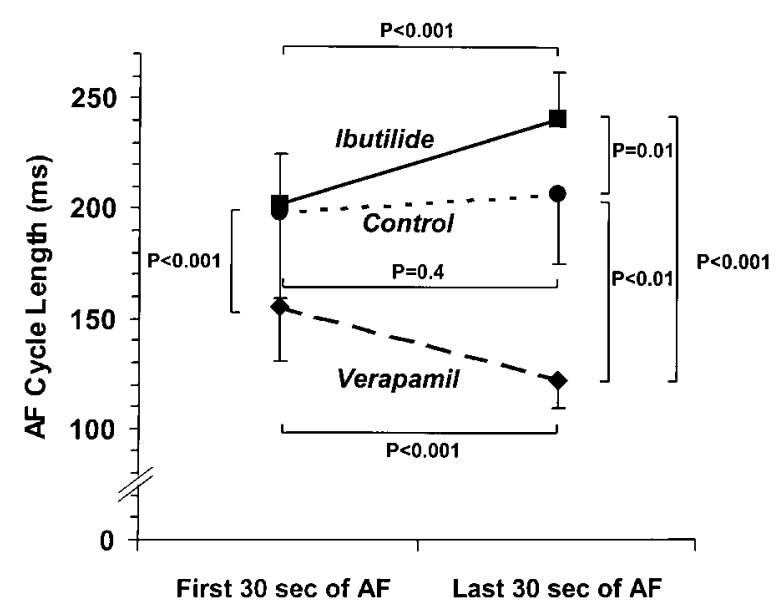

Figure 2. Mean atrial fibrillation $(A F)$ cycle length during the first and last 30 seconds of induced $A F$ in the verapamil, ibutilide, and control groups.

\section{Effects of Verapamil and Ibutilide in the Absence of AF}

After infusion of verapamil during sinus rhythm, there were no changes in atrial ERP at either drive CL (Table 3). After infusion of ibutilide during sinus rhythm, the first postinfusion atrial ERP was significantly longer than baseline at both drive CLs; atrial ERP then remained unchanged during subsequent measurements (Table 4).

\section{Discussion}

\section{Main Findings}

The main findings of this study are as follows. (1) Intravenous verapamil shortens, whereas ibutilide lengthens, the CL of induced AF. (2) Verapamil significantly prolongs the duration of induced episodes of $\mathrm{AF}$ compared with ibutilide and control groups. (3) Ibutilide is more effective than verapamil in preventing the acute effects of a severalminute episode of AF on the atrial ERP. (4) The suscepti-

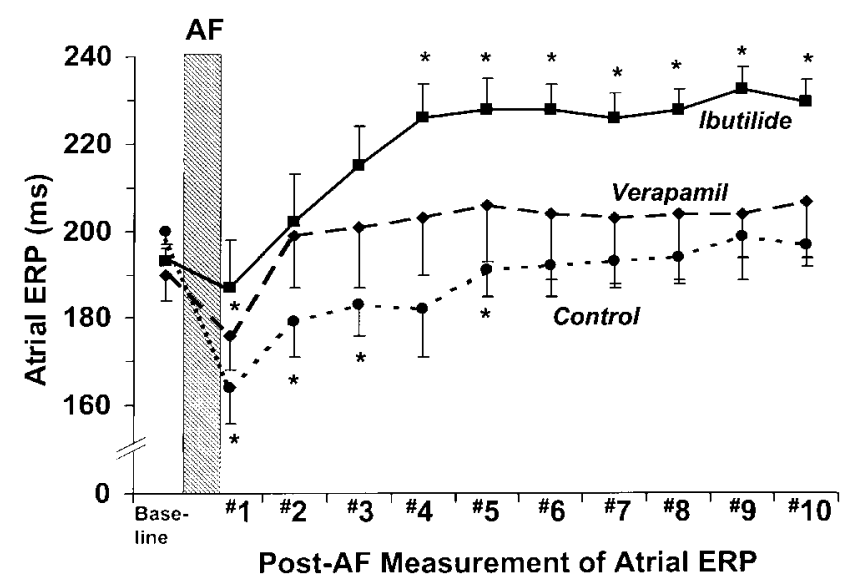

Figure 3. Serial measurements of atrial effective refractory period (ERP) at a basic drive cycle length of $350 \mathrm{~ms}$ upon resumption of sinus rhythm after induced atrial fibrillation (AF; hatched box) in the verapamil, ibutilide, and control groups. Mean atrial ERPs are shown. Error bars signify 1 SEM. $* P<0.05$ vs baseline. 


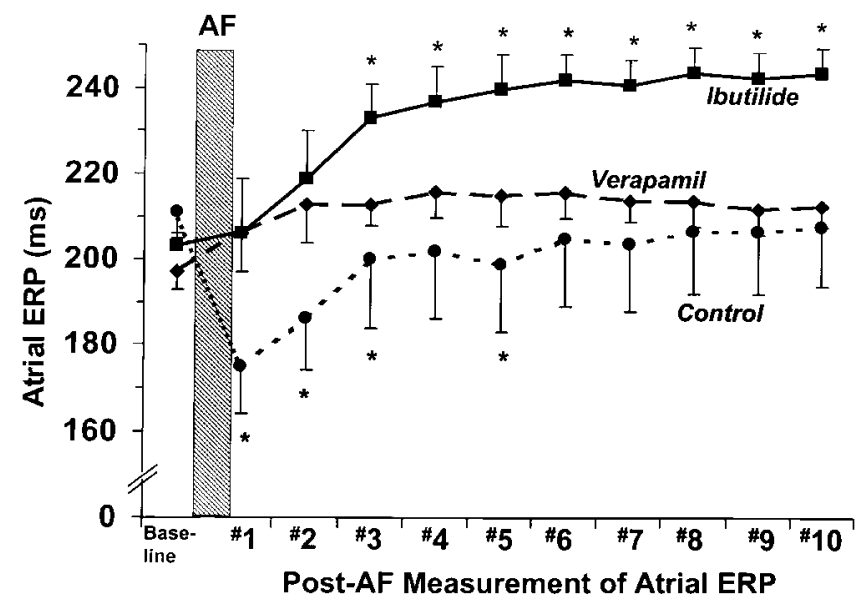

Figure 4. Serial measurements of atrial effective refractory period (ERP) at a basic dive cycle length of $500 \mathrm{~ms}$ upon resumption of sinus rhythm after induced atrial fibrillation (AF; hatched box) in the verapamil, ibutilide, and control groups. Format as in Figure 3.

bility to reinduction of $\mathrm{AF}$ episodes lasting $>10$ minutes shortly after conversion to sinus rhythm is attenuated to a greater degree by ibutilide than by verapamil. (5) In the absence of $\mathrm{AF}$, ibutilide lengthens and verapamil has no effect on atrial ERP.

\section{Effects on AFCL and Duration}

Previous studies demonstrated that AFCL correlates with atrial ERP. ${ }^{16,17}$ Therefore, the observation in the present study that verapamil shortened AFCL implies that it also shortened atrial ERP. In prior studies, verapamil's effect on atrial ERP was measured during sinus rhythm, and verapamil was found to either prolong or have no effect on atrial ERP. ${ }^{2,4}$ Therefore, the effect of verapamil on atrial refractoriness may be variable, depending on the atrial rate.

Verapamil blocks $\mathrm{I}_{\mathrm{Ca}}$, resulting in a decrease in the plateau calcium current and shortening of action potential duration and ERP. ${ }^{18}$ However, verapamil also blocks $\mathrm{I}_{\mathrm{Kr}}$, thereby lengthening ERP. ${ }^{19}$ The effects of $\mathrm{I}_{\mathrm{Kr}}$ blockade at relatively slow atrial rates explain why verapamil may lengthen or have no effect on ERP during sinus rhythm. However, at rapid rates, $\mathrm{I}_{\mathrm{Ca}}$ blockade by verapamil is enhanced, ${ }^{20}$ whereas the effects of $\mathrm{I}_{\mathrm{Kr}}$ blockade are attenuated. ${ }^{21}$ These rate-dependent effects of verapamil were reported as accounting for the shortening of atrial ERP and AFCL in $\operatorname{dogs}^{22}$ and may explain why verapamil shortened $\mathrm{CL}$ during $\mathrm{AF}$ in the present study.

A decrease in atrial ERP during AF in turn shortens the atrial wavelength, which is the product of refractory period and conduction velocity. ${ }^{23}$ Shortening of atrial wavelength promotes the initiation and persistence of $\mathrm{AF}^{1}$ and may explain why the duration of induced $\mathrm{AF}$ in this study was significantly longer in the verapamil group than in the ibutilide or control groups. A prior study also reported that verapamil prolongs the duration of AF. ${ }^{10}$

In line with the results of a prior study ${ }^{24}$ and in contrast to verapamil, ibutilide was found to lengthen the CL of induced $\mathrm{AF}$, implying that it increased atrial ERP during AF. In addition, ibutilide resulted in significant prolongation of atrial ERP several minutes after resumption of sinus rhythm. Furthermore, as found in the present study, prior studies demonstrated that ibutilide lengthens atrial ERP during sinus rhythm. ${ }^{25,26}$ Therefore, in contrast to verapamil, ibutilide appears to consistently prolong atrial refractoriness during sinus rhythm, during AF, and within several minutes after conversion of AF to sinus rhythm.

\section{Effects of Verapamil and Ibutilide on AF-Induced Shortening of Atrial ERP}

When verapamil was infused during sinus rhythm, atrial ERP remained unchanged. This indicates that attenuation of the shortening of ERP by verapamil that occurs post-AF is attributable to direct antagonism of the effects of AF and not to direct lengthening of atrial ERP that simply offsets the AF-induced shortening of ERP.

On the other hand, when ibutilide was infused during sinus rhythm, atrial ERP quickly lengthened and then remained stable, whereas when it was infused during AF, ERP gradually lengthened over several minutes to its maximum value. This suggests that the absence of a change in atrial ERP immediately upon resumption of sinus rhythm may

TABLE 3

Effect of Verapamil on Atrial ERP at Basic Drive Cycle Lengths of 350 and $500 \mathrm{msec}$ in the Absence of AF, in Five Patients Each

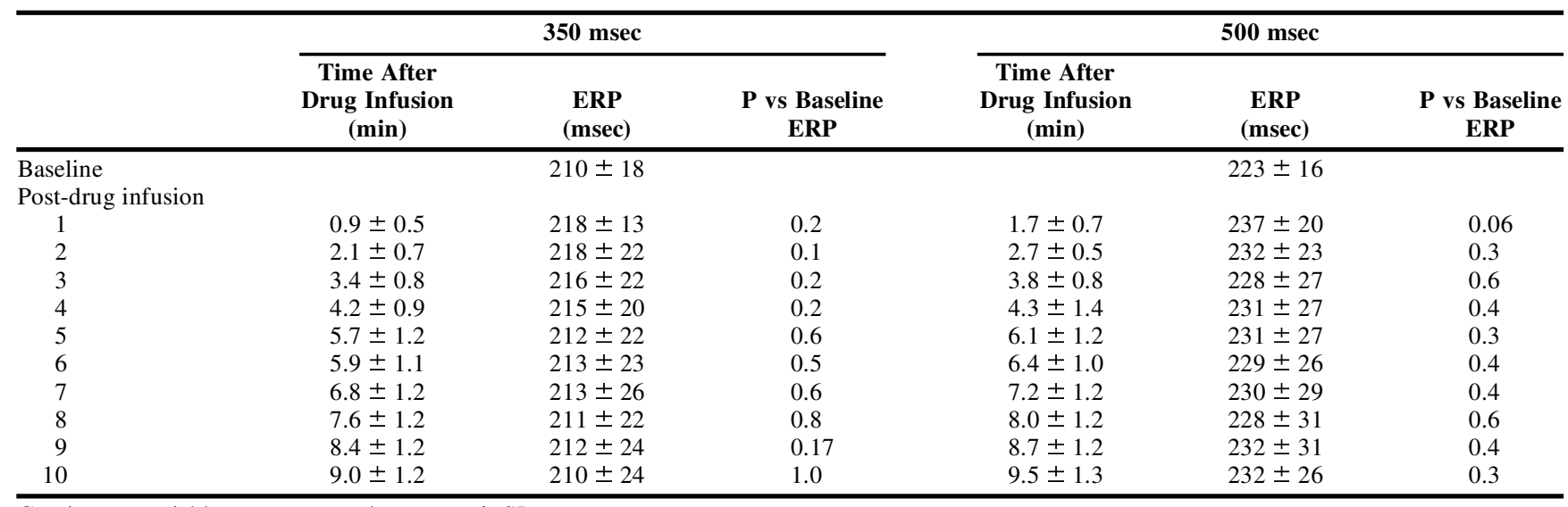


TABLE 4

Effect of Ibutilide on Atrial ERP at Basic Drive Cycle Lengths of 350 and $500 \mathrm{msec}$ in the Absence of AF, in Five Patients Each

\begin{tabular}{|c|c|c|c|c|c|c|}
\hline & \multicolumn{3}{|c|}{$350 \mathrm{msec}$} & \multicolumn{3}{|c|}{$500 \mathrm{msec}$} \\
\hline & $\begin{array}{l}\text { Time After } \\
\text { Drug Infusion } \\
\text { (min) }\end{array}$ & $\begin{array}{c}\text { ERP } \\
(\mathrm{msec})\end{array}$ & $\begin{array}{c}\text { P vs Baseline } \\
\text { ERP }\end{array}$ & $\begin{array}{l}\text { Time After } \\
\text { Drug Infusion } \\
\text { (min) }\end{array}$ & $\begin{array}{c}\text { ERP } \\
(\text { msec })\end{array}$ & $\begin{array}{c}\text { P vs Baseline } \\
\text { ERP }\end{array}$ \\
\hline Baseline & & $192 \pm 19$ & & & $196 \pm 20$ & \\
\hline \multicolumn{7}{|l|}{ Post-drug infusion } \\
\hline 1 & $1.1 \pm 0.9$ & $221 \pm 30$ & 0.01 & $1.9 \pm 0.8$ & $234 \pm 26$ & 0.001 \\
\hline 2 & $2.4 \pm 1.0$ & $222 \pm 26$ & 0.005 & $2.9 \pm 1.0$ & $234 \pm 27$ & 0.001 \\
\hline 3 & $3.3 \pm 0.9$ & $221 \pm 29$ & 0.01 & $3.9 \pm 1.0$ & $237 \pm 34$ & 0.007 \\
\hline 4 & $4.5 \pm 1.4$ & $222 \pm 24$ & 0.002 & $5.1 \pm 1.6$ & $232 \pm 31$ & 0.009 \\
\hline 5 & $5.4 \pm 1.6$ & $223 \pm 32$ & 0.01 & $5.9 \pm 1.5$ & $230 \pm 27$ & 0.004 \\
\hline 6 & $6.3 \pm 1.5$ & $224 \pm 25$ & 0.003 & $7.1 \pm 1.3$ & $233 \pm 27$ & 0.002 \\
\hline 7 & $7.5 \pm 1.4$ & $225 \pm 29$ & 0.008 & $7.8 \pm 1.4$ & $232 \pm 28$ & 0.005 \\
\hline 8 & $8.2 \pm 1.4$ & $223 \pm 25$ & 0.005 & $8.7 \pm 1.5$ & $231 \pm 26$ & 0.003 \\
\hline 9 & $9.1 \pm 1.4$ & $219 \pm 24$ & 0.004 & $9.7 \pm 1.5$ & $236 \pm 23$ & 0.001 \\
\hline 10 & $10.0 \pm 1.5$ & $219 \pm 19$ & 0.004 & $10.7 \pm 1.5$ & $233 \pm 21$ & $<0.001$ \\
\hline
\end{tabular}

Continuous variables are expressed as mean \pm SD.

$\mathrm{AF}=$ atrial fibrillation; $\mathrm{ERP}=$ effective refractory period.

have reflected a direct effect of ibutilide on atrial refractoriness that offset the shortening effect of AF on ERP, with the lengthening effect of ibutilide on refractoriness becoming progressively more manifest as the effects of AF dissipated.

Although verapamil blunted the effect of AF on post-AF ERP in this study, the magnitude of the effect was not as great as in a prior study in which verapamil was found to completely prevent shortening of atrial refractoriness after an episode of AF. ${ }^{4}$ There are three possible explanations for this discrepancy. First, the total dose of verapamil administered in the present study $(10.1 \pm 1.7 \mathrm{mg})$ was lower than in the prior study $(14.7 \pm 2.7 \mathrm{mg})$. Second, the entire dose of verapamil was infused before the induction of $\mathrm{AF}$ in the prior study but not in the present study. Third, pharmacologic autonomic blockade was used in the prior study, ${ }^{4}$ but in the present study, autonomic blockade was not used in order to more closely mimic a typical clinical scenario. It is likely that induction of $\mathrm{AF}$ and/or transthoracic cardioversion resulted in sympathetic activation, ${ }^{27}$ and a prior study demonstrated that verapamil's effects are reversed by betaadrenergic stimulation. ${ }^{28}$ These factors may explain why verapamil did not completely prevent the post-AF shortening of atrial refractoriness observed in prior studies.

\section{Effects on Susceptibility to Reinduction of AF}

Based on the concept of atrial wavelength, prolongation of atrial ERP diminishes the probability that AF will be

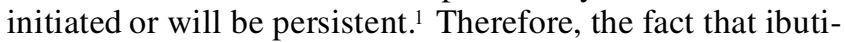
lide prolonged the post-AF atrial ERP compared to baseline, whereas verapamil simply attenuated the shortening of atrial ERP observed in the control group, explains why ibutilide was more effective than verapamil in reducing the susceptibility toward reinduction of episodes of $\mathrm{AF}$ lasting $>10$ minutes shortly after conversion of an episode of AF to sinus rhythm.

\section{Study Limitations}

One limitation of this study is that ERP was measured only at one site in the right atrium. A second limitation is that none of the subjects had heart disease; therefore, the findings may not apply to patients with structurally abnormal atria. A third limitation is that the total dosages of verapamil and ibutilide administered to the subjects in this study were variable. The intent of this study was to determine the effects of verapamil and ibutilide administered during AF, not during sinus rhythm. Because the duration of $\mathrm{AF}$ was variable between subjects and because the drugs were administered as infusions as opposed to bolus doses, this limitation was unavoidable.

\section{Conclusion}

The findings of this study have interesting mechanistic and clinical implications regarding the effects of verapamil and ibutilide on AF. Verapamil shortens atrial ERP during $\mathrm{AF}$ but attenuates the shortening of atrial ERP that occurs upon conversion of AF to sinus rhythm. This explains why verapamil promotes the continuation of an episode of $\mathrm{AF}$ and yet diminishes the susceptibility toward reinduction of $\mathrm{AF}$ once the original episode has converted to sinus rhythm. Ibutilide's effects on atrial refractoriness are opposite to those of verapamil during AF, yet they are qualitatively similar during sinus rhythm after an episode of AF. These findings demonstrate that the effects of antiarrhythmic agents during AF may be dissociated from their immediate post-AF effects.

A clinical implication of the results of this study is that intravenously administered verapamil may be a suboptimal agent for rate control during AF. Although verapamil is effective in reducing the ventricular rate, ${ }^{29}$ the findings of this study suggest that verapamil is likely to shorten AFCL, thereby diminishing the probability of spontaneous conversion to sinus rhythm. It will be important to determine whether this finding applies to other calcium channel blockers, such as diltiazem, which is commonly used intravenously for acute rate control.

A second clinical implication of the findings of this study has to do with the phenomenon of immediate recurrence of AF after cardioversion. A recent study demonstrated that intravenously administered verapamil was effective in maintaining sinus rhythm in $47 \%$ of patients with immediate recurrences of $\mathrm{AF}$ after transthoracic cardioversion. ${ }^{8}$ 
Based on the effects of verapamil and ibutilide on the susceptibility to pacing-induced AF, the findings of this study suggest that ibutilide may be more effective than verapamil in preventing immediate recurrences of $\mathrm{AF}$ after cardioversion. This issue also requires additional investigation.

\section{References}

1. Wijffels MCEF, Kirchhof CJHJ, Dorland R, Allessie MA: Atrial fibrillation begets atrial fibrillation: A study in awake chronically instrumented goats. Circulation 1995;92:1954-1968.

2. Goette A, Hoeneycutt C, Langberg JJ: Electrical remodeling in atrial fibrillation: Time course and mechanisms. Circulation 1996;94:29682974.

3. Daoud EG, Bogun F, Goyal R, Harvey M, Man KC, Strickberger SA, Morady F: Effect of atrial fibrillation on atrial refractoriness in humans. Circulation 1996;94:1600-1606.

4. Daoud EG, Knight BP, Weiss R, Bahu M, Paladino W, Goyal R, Man KC, Strickberger SA, Morady F: Effect of verapamil and procainamide on atrial fibrillation-induced electrical remodeling in humans. Circulation 1997;96:1542-1550.

5. Tieleman RG, De Langen C, Van Gelder IC, de Kam PJ, Grandjean J, Bel KJ, Wijffels MC, Allessie MA, Crijns HJ: Verapamil reduces tachycardia-induced electrical remodeling of the atria. Circulation 1997;95:1945-1953

6. Tieleman RG, Van Gelder IC, Crijns HJ, De Kam PJ, Van Den Berg MP, Haaksma J, Van Der Woude HJ, Allessie MA: Early recurrence of atrial fibrillation after electrical cardioversion: A result of fibrillation-induced electrical remodeling of the atria? J Am Coll Cardiol 1998;31:167-1973.

7. De Simone A, Stabile G, Vitale DF, Turco P, Di Stasio M, Petrazzuoli F, Gasparini M, De Matteis C, Rotunno R, Di Napoli T: Pretreatment with verapamil in patients with persistent or chronic atrial fibrillation who underwent electrical cardioversion. J Am Coll Cardiol 1999;34: 810-814.

8. Daoud EG, Hummel JD, Augostini R, Williams S, Kalbfleisch SJ: Effect of verapamil on immediate recurrence of atrial fibrillation. J Cardiovasc Electrophysiol 2000;11:1231-1237.

9. Lee SH, Yu WC, Cheng JJ, Hung CR, Ding YA, Chang MS, Chen SA: Effect of verapamil on long-term tachycardia-induced atrial electrical remodeling. Circulation 2000;101:200-206.

10. Shenasa M, Kus T, Fromer M, LeBlanc RA, Dubuc M, Nadeau R: Effect of intravenous and oral calcium antagonists (diltiazem and verapamil) on sustenance of atrial fibrillation. Am J Cardiol 1988;62: 403-407.

11. Wesley RC, Farkhani F, Morgan D, Zimmerman D: Ibutilide: Enhanced defibrillation via plateau sodium current activation. Am J Physiol 1993;264:1269-1274

12. Oral H, Souza JJ, Michaud GF, Knight BP, Goyal R, Strickberger SA, Morady F: Facilitating transthoracic cardioversion of atrial fibrillation with ibutilide pretreatment. N Engl J Med 1999;340:1849-1854

13. Howard PA. Ibutilide: An antiarrhythmic agent for the treatment of atrial fibrillation or flutter. Ann Pharmacother 1999;33:38-46.

14. Reiter MJ, Shand DG, Aanonsen LA, Wagoner R, McCarthy E,
Pritchett EL: Pharmacokinetics of verapamil: Experience with a sustained intravenous infusion regimen. Am J Cardiol 1982;50:716-721.

15. Ellenbogen KA, Stambler BS, Wood MA, Sager PT, Wesley RC Jr, Meissner MC, Zoble RG, Wakefield LK, Perry KT, Vanderlugt JT: Efficacy of intravenous ibutilide for rapid termination of atrial fibrillation and atrial flutter: A dose-response study. J Am Coll Cardiol 1996;28:130-136.

16. Capucci A, Biffi M, Boriani G, Ravelli F, Nollo G, Sabbatani P, Orsi C, Magnani B: Dynamic electrophysiological behavior of human paroxysmal atrial fibrillation. Circulation 1995;92:1193-1202.

17. Kim KB, Rodefeld MD, Schuessler RB, Cox JL, Boineau JP: Relationship between local atrial fibrillation interval and refractory period in the isolated canine atrium. Circulation 1996;94:2961-2967.

18. Li GR, Nattel S: Properties of human atrial $\mathrm{I}_{\mathrm{Ca}}$ at physiological temperatures and relevance to action potential. Am J Physiol 1997; 272:H227-H235.

19. Zhang S, Zhou Z, Gong Q, Machielski JL, January CT: Mechanism of block and identification of the verapamil binding domain to HERG potassium channels. Circ Res 1999;84:989-998.

20. Ellenbogen KA, German LD, O'Callaghan WG, Colavita PG, Marchese AC, Gilbert MR, Strauss HC: Frequency-dependent effects of verapamil on atrioventricular nodal conduction in man. Circulation 1985;72:344-352.

21. Nattel S, Liu L, St.-Georges D: Effects of the novel antiarrhythmic agent azimilide on experimental atrial fibrillation and electrophysiological properties. Cardiovasc Res 1998;37:627-635.

22. Benardeau A, Fareh S, Nattel S: Effects of verapamil on atrial fibrillation and its electrophysiological determinants in dogs. Cardiovasc Res 2001;50:85-96.

23. Wiener N, Rosenblueth A: The mathematical formulation of the problem of conduction of the impulses in a network of connected excitable elements, specifically in cardiac muscle. Arch Inst Cardiol Met 1946; $16: 205-265$

24. Stambler BS, Wood MA, Ellenbogen KA: Antiarrhythmic actions of intravenous ibutilide compared with procainamide during human atrial flutter and fibrillation. Circulation 1997;96:4298-4306.

25. Buchanan LV, Kabell GG, Brunden MN, Gibson JK: Comparative assessment of ibutilide, d-sotalol, clofilium, E-4031, and UK-68,798 in a rabbit model of proarrhythmia. J Cardiol Pharmacol 1993;220:540549 .

26. Stambler BS, Wood MA, Ellenbogen KA: Antiarrhythmic actions of intravenous ibutilide compared with procainamide during human atrial flutter and fibrillation: Electrophysiological determinants of enhanced conversion efficacy. Circulation 1997;96:4298-4306.

27. Morady F, DiCarlo LA, Halter JB, de Buitleir M, Krol RB, Baerman JM: The plasma catecholamine response to ventricular tachycardia induction and external countershock during electrophysiologic testing. J Am Coll Cardiol 1986;8:584-591.

28. Morady F, Kou WH, Kadish AH, Toivonen LK, Kushner JA, Schmaltz $S$ : Epinephrine-induced reversal of verapamil's electrophysiologic and therapeutic effects in patients with paroxysmal supraventricular tachycardia. Circulation 1989;79:783-790.

29. Waxman HL, Myerburg RJ, Appel R, Sung JR: Verapamil for control of ventricular rate in paroxysmal supraventricular tachycardia and atrial fibrillation or flutter. Ann Intern Med 1981;94:1-6. 